Article

\title{
Sheep Wool as a Construction Material for Energy Efficiency Improvement
}

\section{Azra Korjenic ${ }^{1, *}$, Sanela Klarić ${ }^{2}$, Almedina Hadžić ${ }^{3}$ and Sinan Korjenic ${ }^{4}$}

1 Institute for Building Construction and Technology, Research Centre of Building Physics and Sound Protection, Vienna University of Technology, Karlsplatz 13/206-2, 1040 Vienna, Austria

2 Department of Architecture, International Burch University, Francuske revolucije bb, 71000 Sarajevo, Bosnia and Herzegovina; E-Mail: sanela.klaric@ibu.edu.ba

3 Department of Product Design, Academy of Fine Arts, University of Sarajevo, Obala Kulina Bana 7/II, 71000 Sarajevo, Bosnia and Herzegovina; E-Mail: almedina_hadzic@yahoo.com

4 Institute for Building Construction and Technology, Research Centre of Building Construction and Technology, Vienna University of Technology, Karlsplatz 13/206-4, 1040 Vienna, Austria; E-Mail: sinan.korjenic@tuwien.ac.at

* Author to whom correspondence should be addressed; E-Mail: azra.korjenic@tuwien.ac.at; Tel.: +43-1-58801-20662; Fax: +43-1-58801-920662.

Academic Editor: Hossam A. Gabbar (Gaber)

Received: 12 May 2015 / Accepted: 9 June 2015 / Published: 16 June 2015

\begin{abstract}
The building sector is responsible for $40 \%$ of the current $\mathrm{CO}_{2}$ emissions as well as energy consumption. Sustainability and energy efficiency of buildings are currently being evaluated, not only based on thermal insulation qualities and energy demands, but also based on primary energy demand, $\mathrm{CO}_{2}$ reductions and the ecological properties of the materials used. Therefore, in order to make buildings as sustainable as possible, it is crucial to maximize the use of ecological materials. This study explores alternative usage of sheep wool as a construction material beyond its traditional application in the textile industry. Another goal of this research was to study the feasibility of replacement of commonly used thermal insulations with natural and renewable materials which have better environmental and primary energy values. Building physics, energy and environmental characteristics were evaluated and compared based on hygrothermal simulation and ecological balance methods. The observations demonstrate that sheep wool, compared with mineral wool and calcium silicate, provides comparable thermal insulation characteristics, and in some applications even reveals better performance.
\end{abstract}


Keywords: energy efficiency; primary energy reduction; $\mathrm{CO}_{2}$ reduction; natural and renewable building materials; sheep wool; hygrothermal simulation; ecological balance method

\section{Introduction}

The design of environmentally friendly buildings is currently one of the more compelling issues. The basic premise for eco-design is that human health depends on the quality of air and water as well as on the quality of soil from which foodstuffs are produced. In order to address the misunderstanding as to what constitutes eco-design, it is important to highlight that green design is not just about low-energy consumption, but also about environmental integration through smart design.

The new approaches to energy-efficient and sustainable building designs not only focus on goals to decrease energy consumption, but also to lower construction costs through the application of natural and locally available materials. Environmental awareness consists of energy savings as well as ecologically sound construction, and the materials and methods used throughout all the stages of the life cycle of a building. In this regard, minimum energy input, sustainable resource consumption and minimized pollution should be a part of the production, installation and use of insulation materials [1]. The Directive 2010/31/EU of the European Parliament and the European Council (dated 19 May 2010) on the energy performance of buildings require that "the energy performance certificate should also provide information about the actual impact of heating and cooling on the energy needs of the building, on its primary energy consumption and on its carbon dioxide emissions" [2].

Therefore, from the perspective of sustainable development it is important to choose easily recyclable, renewable, locally available and environmentally friendly raw materials, such as timber, clay, stone, straw, bio-based fibers and sheep wool, provided that any further processing is carried out with low energy consumption. The rapidly rising fears that raw materials and energy resources would eventually be depleted, in addition to the concerns regarding excessive air pollution are encouraging scientific and cross-disciplinary engagement on this topic. There are fundamental differences between the engineering and the ecological approaches to green or eco-design. In the engineering approach, the designer begins with the final picture of the desired outcome governed by the process of efficiency that culminates in production. In contrast, the ecological design approach begins with environmental discernment (seeing what there is) and is governed by the process of achieving environmental harmony.

In both aforementioned approaches, and more emphasis ought to be placed on the non-toxic materials, transformability and recyclability. In addition to energy, demanding technologies are shifted towards organic materials - the natural raw materials that meet the majority of requirements for alternative resource, sustainable development and innovative green technologies. Recent investigations were carried out with natural materials, indicating that they are comparable with standard building materials.

The demand for green building materials, especially insulating materials from renewable resources, is sharply rising [3]. Sheep wool as a natural material has been traditionally used in the textile industry for the manufacture of conventional woolen products, such as carpets, garments, curtains, covers and bedding. Even though sheep wool insulation is a relatively well developed marked in Western Europe, 
most of the elements made from sheep wool in Bosnia and Herzegovina (BiH) building sector have been exclusively used for interior decoration purposes.

The application of natural materials from renewable resources with comparable physical and mechanical properties to conventional materials has become more important. With respect to recent developments in science and technology, it is safe to say that thermal insulators made from natural materials are likely to become a suitable alternative to commonly used boards made from different man-made materials (mineral wool, polystyrene or polyurethane). The properties of insulating boards made of organic fibres are fully comparable with common insulating boards made from other materials [4]. The use of natural materials in buildings is beneficial to human health [5]. Expanded polystyrene (EPS) is one of the most common materials used as thermal insulation in buildings today, and its use has been connected with serious safety, environmental and health concerns as it has extremely high flammability and produces toxic fumes [6].

The Life Cycle Assessment (LCA) approach has become a common tool for the assessment of prime energy and $\mathrm{CO}_{2}$ emissions. The comparison of primary energy need and $\mathrm{CO}_{2}$ emission between $1 \mathrm{~m}^{3}$ of sheep wool insulation and mineral wool demonstrates that the former produces almost $5.4 \mathrm{~kg}$ of $\mathrm{CO}_{2}$, whereas the $\mathrm{CO}_{2}$ yield of the latter is $135 \mathrm{~kg}$ [7]. With the growing demand for affordable housing and the importance of supporting and stimulating sustainable development, the need for sustainable solutions and clean technologies in this sector is essential for strategic development of less-developed countries. Traditional technologies need to be developed with the aim of achieving more standardized and flexible solutions within the framework of sustainable business models. On the other hand, the environmental and socio-economic performance of the more industrial solutions needs to be improved while maintaining their competitive presence in the market [8]. This research reveals that traditional textile industry technologies and methods used for wool processing, which prove to be far less detrimental to the environment, could be a sustainable answer for insulation panel manufacture and thereby suggest new possibilities in the building industry. Test results with sheep wool indicate the material's excellent performance in the development of building thermal insulation elements.

\section{Sheep Wool Characteristics}

Our presentation of sheep wool includes a historical overview of various uses, mechanical and physical properties and its chemical composition [9] (Table 1).

Table 1. Typical wool average chemical composition.

\begin{tabular}{cccccc}
\hline Element & $\mathbf{C}$ & $\mathbf{H}$ & $\mathbf{O}$ & $\mathbf{N}$ & $\mathbf{S}$ \\
\hline$\%$ & 50 & 7 & $22-25$ & $16-17$ & $3-4$ \\
\hline
\end{tabular}

A single wool fibre may be $18-41 \mu \mathrm{m}$ thick. Its length usually ranges between 4 and $14 \mathrm{~cm}$, but could be longer in some cases. The major characteristics of wool include fineness, length, crimp, colour, strength, uniformity, and the amounts of foreign material in wool grease [10]. Some important characteristics of wool are the following:

- Wool is a natural, renewable and sustainable material;

- It causes no irritation to the eyes, skin or lungs and wool fibres present no hazard to human health; 
- Wool fibres are breathable; unlike fibre glass based products they can absorb and desorb moisture without reducing thermal performance, which make them a perfect insulation material;

- Wool does not support combustion and will extinguish itself in the event of fire;

- Sheep wool is static resistant. Wool has very little tendency to collect static electricity because wool naturally absorbs moisture from the air;

- Wool absorbs noise and reduces noise levels;

- Wool is dirt resistant. Its ability to absorb moisture and therefore its low build-up of static electricity means that wool does not attract lint and dust from the air. The crimp in the fibre and the scales on the surface of the fibre prevents dirt from penetrating into the fabric.

The processing of wool involves four major steps. The first step is shearing, followed by sorting and grading, making yarn and, lastly, making fabric. It is then washed to remove impurities, sand and dust, after which it is dried and then carded. The carding process involves passing the wool through rollers that have thin wire teeth which untangle the fibres and arrange them into a flat sheet that is called a web [11].

\section{Building Physical Examination: Comparison of Three Insulation Materials}

The energy renovation of buildings is currently a high-priority topic, not only in Europe but all over the world. For standard energy renovation, synthetic insulation materials, such as EPS, are used. To meet the European Union requirements and to allow sustainable architecture, new solutions with natural building materials are necessary.

This part presents examinations of insulating wall constructions with various thermal insulation materials as well as a comparison between sheep wool, mineral wool and calcium silicate insulation. A refurbishment of an external wall with internal insulation was investigated and a comparison of different insulation materials was made. Building-physics assessment was conducted regarding the U-value using statistics and Hygrothermal Simulation programs. In addition, ecological balance studies where carried out.

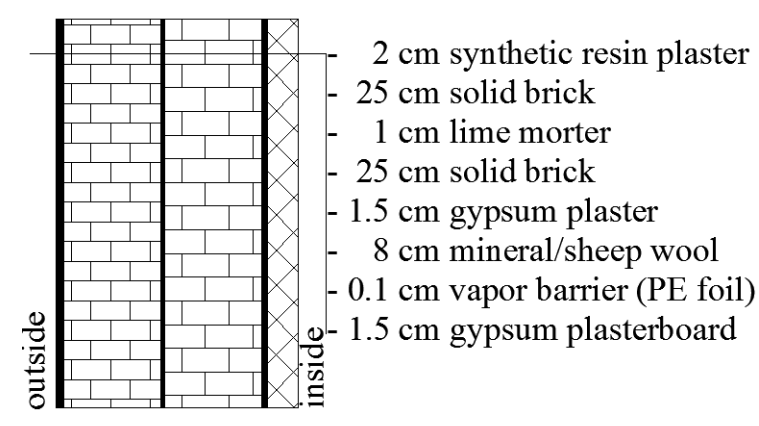

(a)

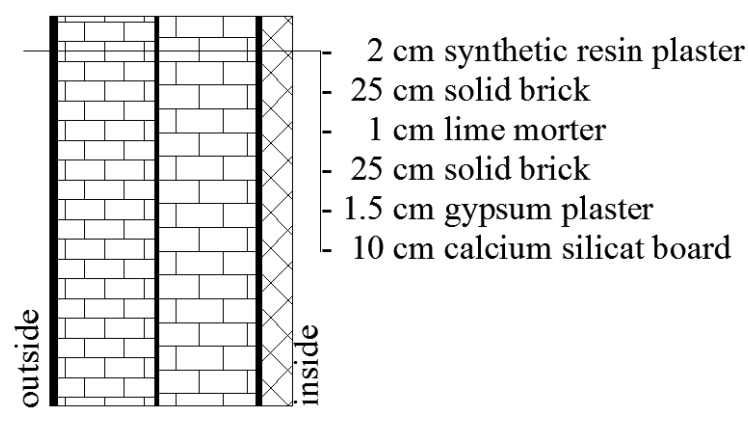

(b)

Figure 1. The structure of a common existing wall that was renovated using an interior insulation: (a) with wool insulation; (b) with calcium silicate board.

Figure 1 illustrates the structure of a common existing wall. The building physics Heat, Air and Moisture simulation program (HAM 3D), developed at the Vienna University of Technology, was used for hygrothermal investigation. The program solves numerical equations for the coupled heat, 
moisture and air transport in porous building materials, given the boundary conditions such as weather, location and materials data.

Table 2. Internal insulation with mineral wool. External wall refurbishment with $8 \mathrm{~cm}$ of mineral wool, internal insulation.

\begin{tabular}{ccccc}
\hline Materials & $\begin{array}{c}\mathbf{d} \\
{[\mathbf{m}]}\end{array}$ & $\begin{array}{c}\boldsymbol{\lambda} \\
{[\mathbf{W} / \mathbf{m K}]}\end{array}$ & $\begin{array}{c}\boldsymbol{\mu} \\
{[-]}\end{array}$ & $\begin{array}{c}\text { Rsi+Rse } \\
{\left[\mathbf{m}^{2} \mathbf{K} / \mathbf{W}\right]}\end{array}$ \\
\hline Air (i und e) & - & - & - & 0.17 \\
Synthetic resin plaster & 0.02 & 0.7 & 50 & - \\
Solid brick & 0.25 & 0.55 & 7 & - \\
Lime mortar & 0.01 & 0.2 & 10 & - \\
Solid brick & 0.25 & 0.55 & 7 & - \\
Gypsum plaster & 0.015 & 0.2 & 10 & - \\
Mineral wool & 0.08 & 0.038 & 1 & - \\
Vapour barrier (PE foil) & 0.01 & 0.23 & 100,000 & - \\
Gypsum plasterboard & 0.015 & 0.2 & 1 & - \\
\hline U-Value & 0.29 & $\mathrm{~W} / \mathrm{m}^{2} \mathrm{~K}$ & & \\
\hline
\end{tabular}

Table 3. Internal insulation with sheep wool. External wall renovation with $8 \mathrm{~cm}$ sheep wool, internal insulation.

\begin{tabular}{ccccc}
\hline Materials & $\begin{array}{c}\mathbf{d} \\
{[\mathbf{m}]}\end{array}$ & $\begin{array}{c}\boldsymbol{\lambda} \\
{[\mathbf{W} / \mathbf{m K}]}\end{array}$ & $\begin{array}{c}\boldsymbol{\mu} \\
{[-]}\end{array}$ & $\begin{array}{c}\text { Rsi+Rse } \\
{\left[\mathbf{m}^{2} \mathbf{K} / \mathbf{W}\right]}\end{array}$ \\
\hline Air (i und e) & - & - & - & 0.17 \\
Synthetic resin plaster & 0.02 & 0.7 & 50 & - \\
Solid brick & 0.25 & 0.55 & 7 & - \\
Lime mortar & 0.01 & 0.2 & 10 & - \\
Solid brick & 0.25 & 0.55 & 7 & - \\
Gypsum plaster & 0.015 & 0.2 & & - \\
Sheep wool & 0.08 & 0.04 & 1 & - \\
Vapour barrier (PE foil) & 0.01 & 0.23 & 100,000 & - \\
Gypsum plasterboard & 0.015 & 0.2 & 1 & - \\
\hline U-Value & 0.30 & $\mathrm{~W} / \mathrm{m}^{2} \mathrm{~K}$ & & \\
\hline
\end{tabular}

Table 4. Internal insulation with calcium silicate board. External wall renovation with $10 \mathrm{~cm}$ calcium silicate board, interior insulation.

\begin{tabular}{ccccc}
\hline Materials & $\begin{array}{c}\mathbf{d} \\
{[\mathbf{m}]}\end{array}$ & $\begin{array}{c}\boldsymbol{\lambda} \\
{[\mathbf{W} / \mathbf{m K}]}\end{array}$ & $\begin{array}{c}\boldsymbol{\mu} \\
{[-]}\end{array}$ & $\begin{array}{c}\text { Rsi+Rse } \\
{\left[\mathbf{m}^{\mathbf{2}} \mathbf{K} / \mathbf{W}\right]}\end{array}$ \\
\hline Air (i und e) & - & - & - & 0.17 \\
Synthetic resin plaster & 0.02 & 0.7 & 50 & - \\
Solid brick & 0.25 & 0.55 & 7 & - \\
Lime mortar & 0.01 & 0.2 & 10 & - \\
Solid brick & 0.25 & 0.55 & 7 & - \\
Gypsum plaster & 0.015 & 0.2 & - & - \\
Calcium silicate board & 0.1 & 0.07 & 10 & \\
\hline U-Value & 0.38 & $\mathrm{~W} / \mathrm{m}^{2} \mathrm{~K}$ & & \\
\hline
\end{tabular}

The HAM 3D program delivers component information such as temperature course, moisture content, partial pressure, relative humidity, capillary pressure, condensate, air flow and the locations of the potential growth of mould and mildew and any other form of decay. 
Building physics simulations of the wall using different insulation materials were carried out in which moisture content and dynamic U-value were examined. U-values calculations of these three variants are presented in Tables 2-4. In the calculations with the HAM 3D program, the building components have been cut into $1 \mathrm{~cm}$ thick layers (fine grid, Figure 2).

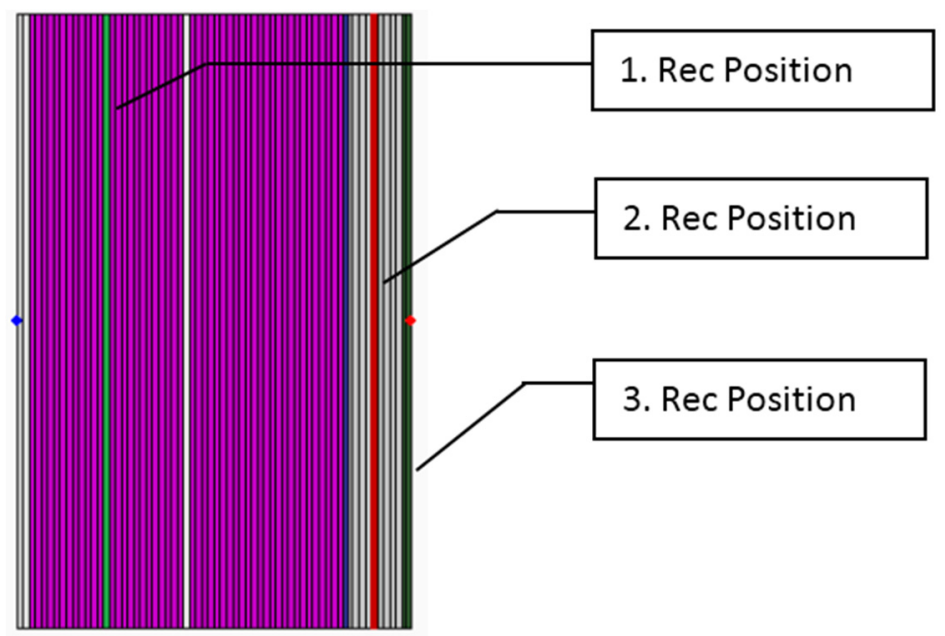

Figure 2. The recorder positions.

Three recorder positions - from which the data were supposed to be analyzed in detail-were placed in the same locations as indicated to ensure a better comparison:

Recorder position 1: external solid brick-centre;

Recorder position 2: old interior plaster;

Recorder position 3: MiWo/sheep wool/CaSi-centre.

Boundary conditions used for the simulation were as follows: Vienna hourly weather data without rain; absorption coefficient of 0.8 ; indoor relative humidity of $40 \%$; Sky-factor of 0.5 . The evaluation of the simulation is performed with four diagrams: Temperature course; Total water content of the construction; Relative humidity in the old interior plaster (Recorder position 2); Relative humidity in the centre of the insulation (Recorder position 3).

Furthermore, the potential for mould growth is presented. The assessment from the HAM 3D is based on studies by Viitanen [12]. The thermal and moisture behaviour of building materials, and subsequently the building envelope, is a significant aspect of the whole building performance [13].

The HAM 3D simulation was carried out for ten years, so that the tendency of the moisture content due to the diffusion can be clearly seen (Figure 3). The red line presents the temperature course.

The total water content is a bit larger in buildings containing wool as compared to other materials. This observation is attributed to wool's moisture absorption characteristic. In both variants, the total water content decreased with time. Relative humidity is a key factor in the mould growth, and the risk of its growth usually starts at $80 \%$ relative humidity for a longer duration of time. Diagrams in Figures 4 and 5 illustrate the variations of the relative humidity in the three investigated variants at two different recorder positions. The openness of the calcium silicate plate allows diffusion of more moisture into the old interior plaster than with the other two variants, and this moisture could be completely dried out. 

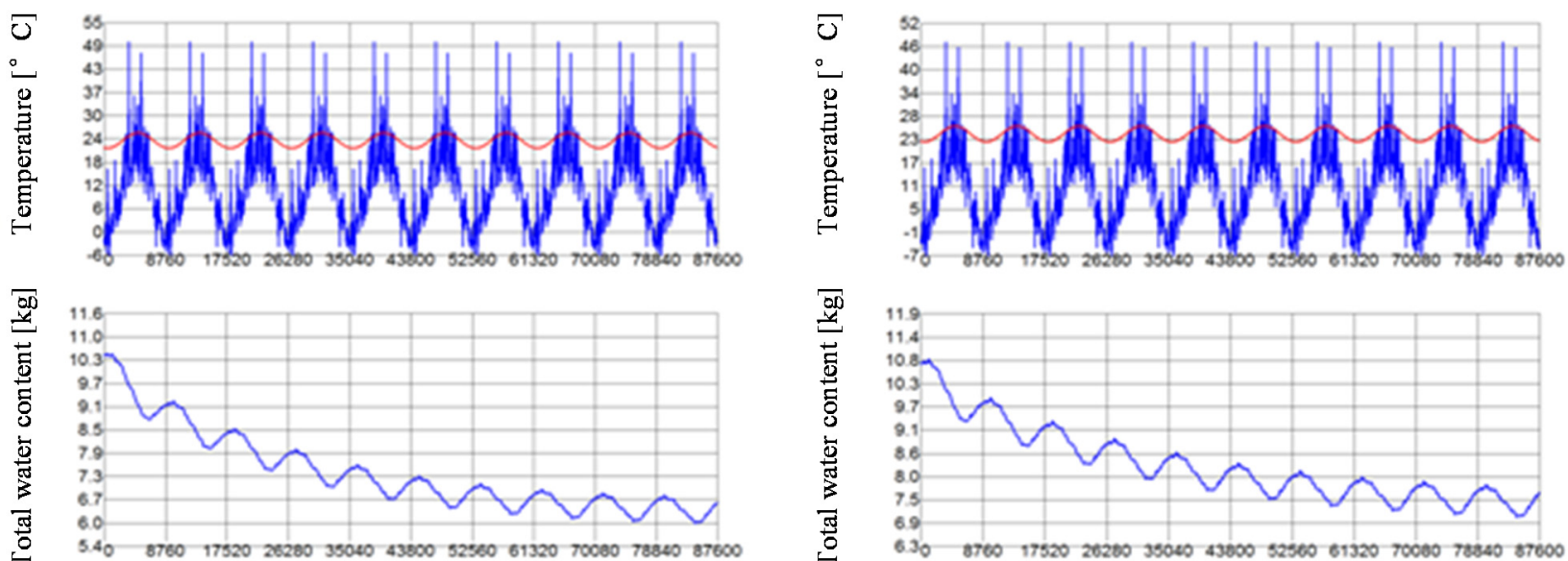

(a) MiWo, Time $[\mathrm{h}]$
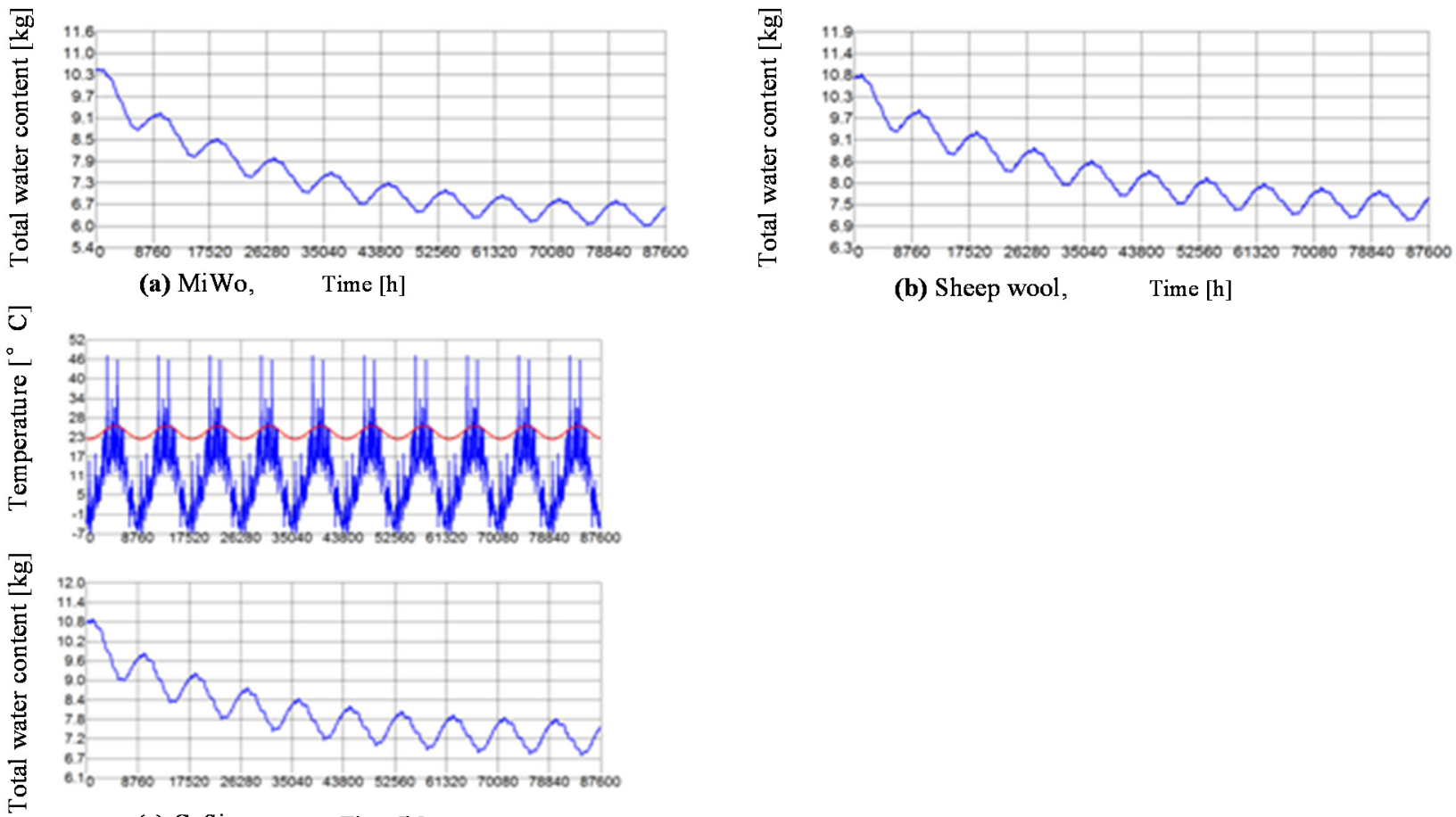

(b) Sheep wool, $\quad$ Time $[\mathrm{h}]$

(c) $\mathrm{CaSi}, \quad$ Time $[\mathrm{h}]$

Figure 3. Temperature: exterior (blue), interior (red) and total water content (a) MiWo;

(b) Sheep wool and (c) CaSi.

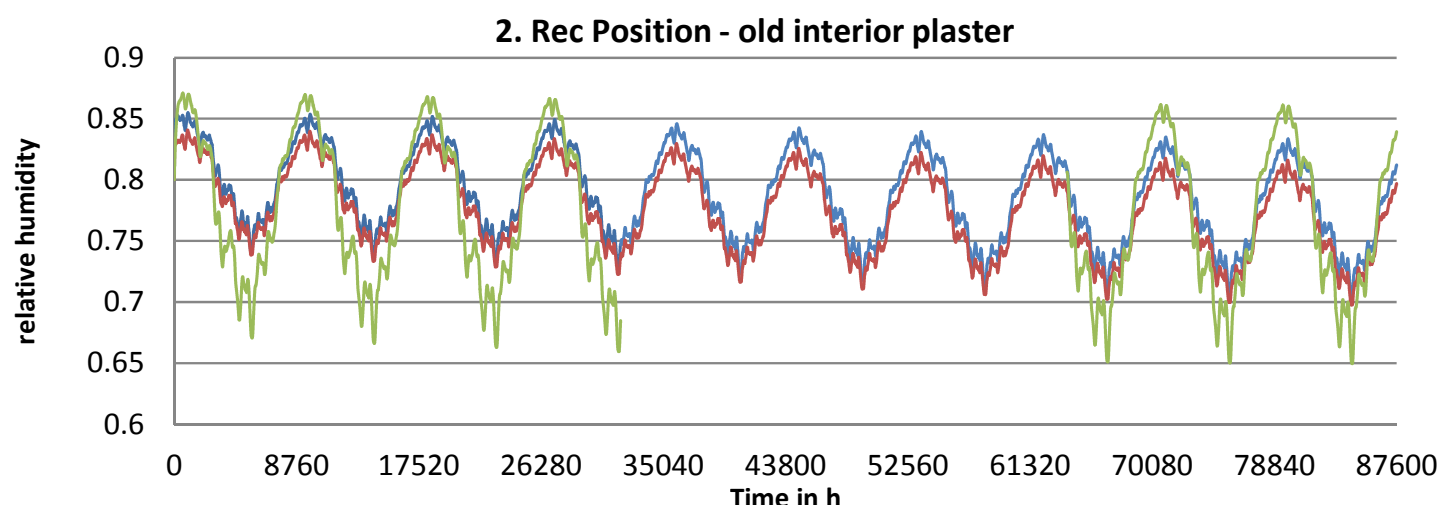

Figure 4. Relative humidity at Rec Position 2, in old interior plaster; (blue) MiWo, (red) Sheep wool and (green) CaSi.

The third recorder position shows that for all three variants, the relative humidity in the middle of the insulation layer remains below $80 \%$, and this results in a minimal to no risk of mould formation. Calcium silicate revealed the least moisture content. In the case of an interior insulation, the potential of mould growth is a very important criterion. The mould growth potential [12] was also simulated using the HAM 3D program. In all three variants, the probability of mould growth in the interior side of old plaster (cold side of the insulation) was found to be the highest. 


\section{Rec Position - middle of insulation}

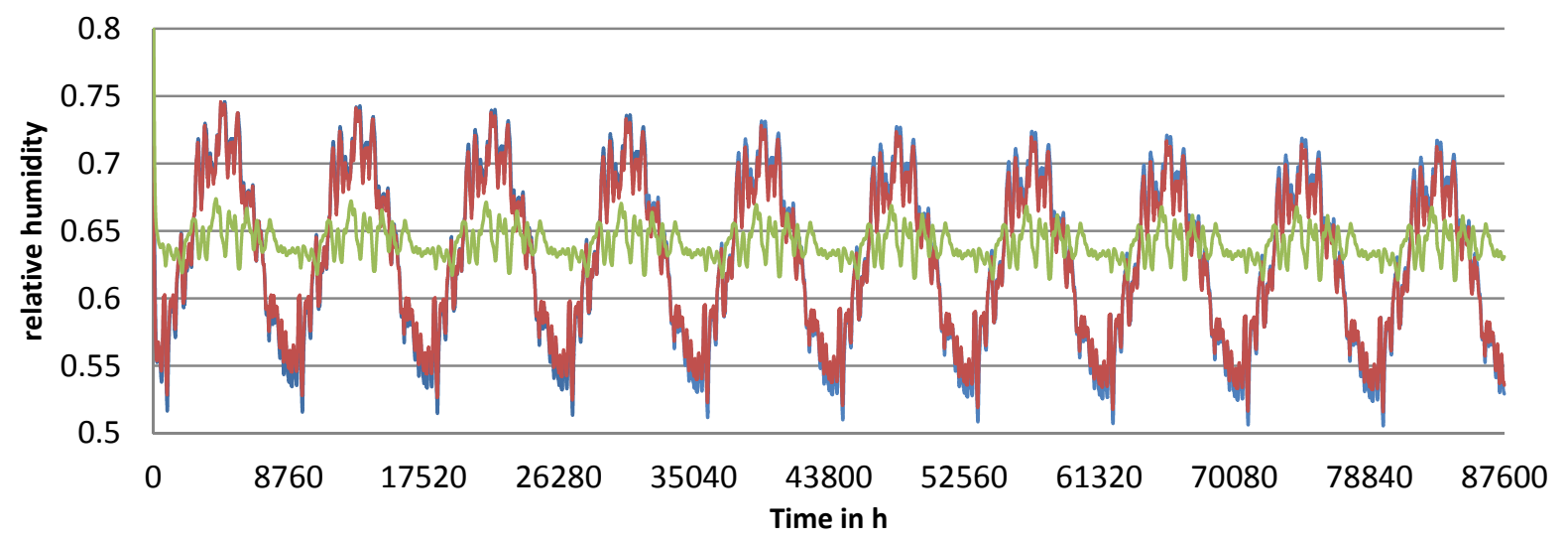

Figure 5. Relative humidity at Rec Position 3, in the middle of insulation; (blue) MiWo, (red) Sheep wool and (green) CaSi.

The calcium silicate board takes up a lot of humidity from the room air and therefore accumulates significant amounts of water on the cold side of the insulation board. However, this could to be released back. Sheep wool also has good absorption/desorption properties, and therefore its risk of mould growth is lower than that for mineral wool. The moisture content in the buildings increases through diffusion. It increases the thermal conductivity of the material, and thereby increases the heat flow and consequently the U-value of the buildings. In fact, at existing conditions, the effect is amplified. All of these attributes result in the smallest U-value in the winter time. The change in the U-value over the course of one year is smaller in a building whose constriction encompasses sheep wool (Table 5). Due to this stable hygrothermal situation is the construction more protected of hygrothermal expansion and contraction, and thereby, the entire component is mechanically less stressed. The average U-value is marginally larger.

Table 5. Impact of seasonal moisture content variations on of the change of $U$-values $\left(\mathrm{W} / \mathrm{m}^{2} \mathrm{~K}\right)$.

\begin{tabular}{cccc}
\hline Material & Maximum & Minimum & Average \\
\hline Mineral wool & 0.38 & 0.2 & 0.29 \\
Sheep wool & 0.33 & 0.29 & 0.31 \\
Calcium silicate & 0.41 & 0.36 & 0.385 \\
\hline
\end{tabular}

Based on the calculation results, it can be stated that thermal insulation made from sheep wool provides comparable characteristics to those made from conventional materials and in some applications, it even performs better. Sheep wool is mainly characterized by high hygroscopicity, which is a material's ability to absorb moisture, and materials with this characteristic also adjust air humidity and hence create a pleasant indoor climate. It has been previously shown that in a component that has up to $20 \%$ moisture content, the weight increase due to this moisture content does not change the thermal conductivity coefficient significantly [4].

The sheep wool as an interior insulation with vapour barrier, is an optimal solution for building physics because of its absorption characteristic and ability to keep the absorbed moisture as well as eventually release it again. It still accumulates moisture on the cold side of the insulation, but less so than insulation made up of the mineral wool. Therefore, the use of sheep wool in combination with 
other renewable resources appears to be the best alternative to reduce the primary energy requirements of a building and thereby meet the energy efficiency and sustainability requirements.

\section{Ecological Balance}

Based on the data from $[1,7,8]$, the three investigated variants were previously compared with regard to their environmental performances in manufacturing, transportation, usage, recycling and release of greenhouse gases (e.g., $\mathrm{CO}_{2}, \mathrm{CH}_{4}$ ) The global warming potential is a variable that describes a material's impact on the environment over the course of 100 years in reference to $\mathrm{CO}_{2}$. The diagram in Figure 6 clearly indicates that sheep wool has a low global warming potential. The variant with calcium silicate requires no vapour barrier and no gypsum board thus the overall design has a smaller $\mathrm{CO}_{2}$-equivalent balance.

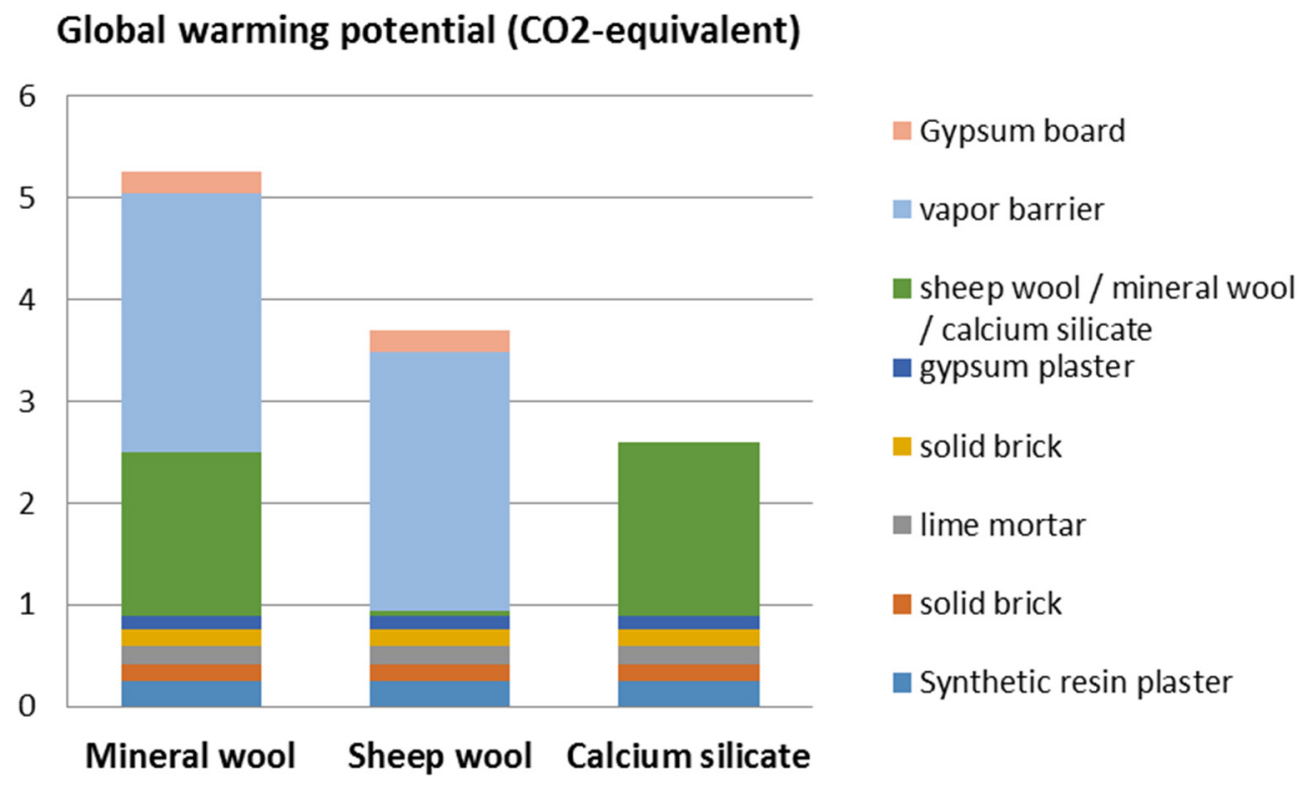

Figure 6. Global warming potential of the constructions with mineral wool, sheep wool and calcium silicate.

A more relevant picture with respect to the negative emission illustrates the global warming potential in relation to the built-in building material compositions. According to the observations, the smallest amount of $\mathrm{CO}_{2}$ emitted from the construction belongs to sheep wool (Figure 7).

One of the most important parameters in the ecological balance is the cumulated energy demand $(\mathrm{KEA}=\mathrm{CED})$ that indicates how much energy a building material or a construction in its life cycle, indirectly or directly, consumes (Figure 8). The CED values of materials are expressed in $\mathrm{MJ} / \mathrm{m}^{3}$, which was converted to $\mathrm{MJ} / \mathrm{m}^{2}$ to make the energy consumption values comparable.

The smallest energy consumption value belongs to calcium silicate board as no vapour barrier is necessary. However, considering only the insulation itself, the sheep wool is the most energy efficient material in this application. 


\section{CO2-equivalent in $\mathrm{kg}$}

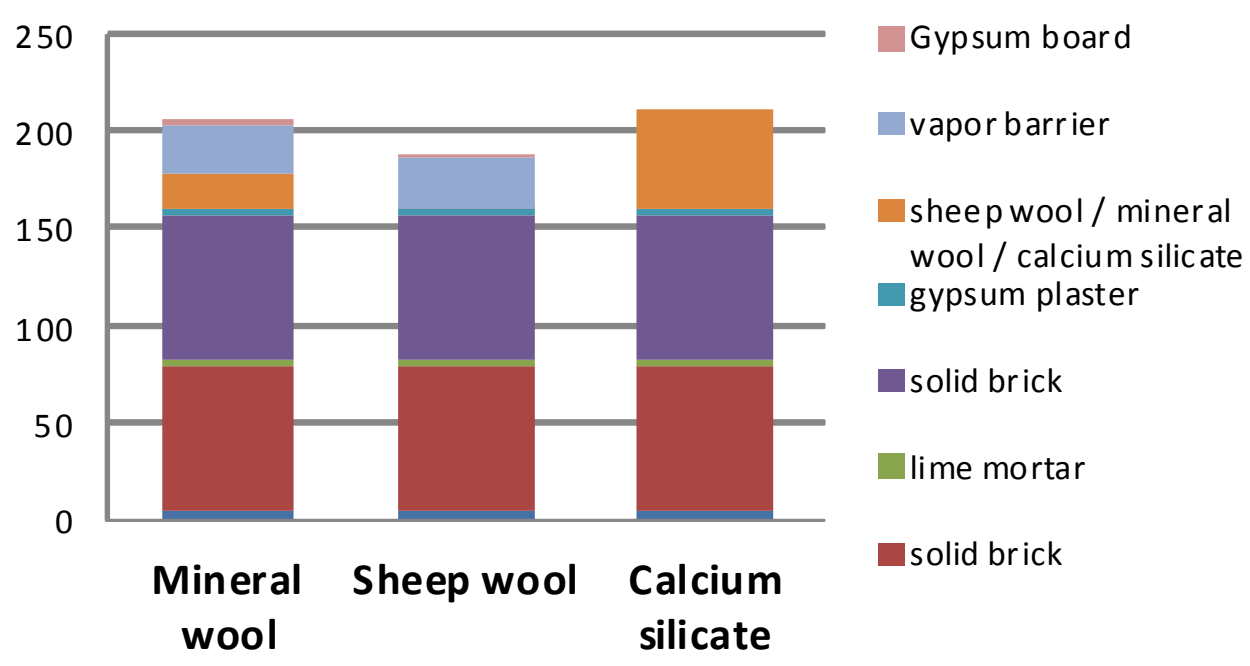

Figure 7. $\mathrm{CO}_{2}$ equivalent in $\mathrm{kg}$ of the constructions with mineral wool, sheep wool and calcium silicate.

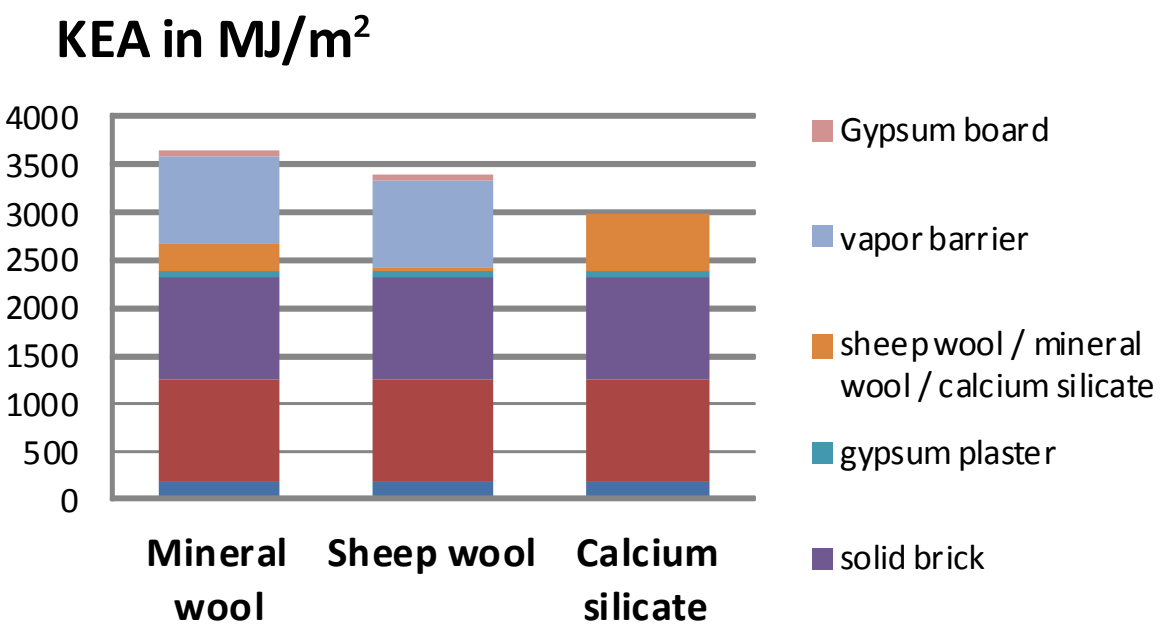

Figure 8. Cumulative energy demand of the constructions with mineral wool, sheep wool and calcium silicate.

\section{Other Aspects Related to Life Cycle Assessment (LCA)}

It is important to have an exact definition of Life Cycle Check (LCC), which is a very simple, practical and useful tool for environmental assessment of products. In the first part of the analysis, a brief step-by-step description of the process is provided. In this paper, a simple LCC method has been used based on the provided numerical data to identify where the environmental impact lies and on which stage of life cycle we should focus on to reduce the negative environmental impact, if there is any. Moreover, the point in such analysis is the benefits and sustainability of sheep wool. Further detailed calculations would be necessary for a precise Life Cycle Assessment (LCA). 


\section{Differences between Life Cycle Assessment (LCA) and Life Cycle Check (LCC)}

\subsection{Life Cycle Assessment}

Life Cycle Assessment can be defined as a compilation and evaluation of the inputs, outputs and potential environmental impacts of a product throughout the life cycle. The life cycle consists of four basic steps, including production of raw materials, manufacturing (packing and distribution), use and maintenance, and disposal of the used product.

The Danish Environmental Protection Agency has initiated activities concerning simplification of LCA in order to meet a growing need in rapid and simple work with LCA. The aim of the LCC is to illustrate the life cycle thinking and to give a tool to perform a preliminary LCA. It is a tool that guides the planning and optimizing the future work for the assessment of environmental impacts of a product. The LCC consists of the following four basic tasks: material, energy, chemicals and issues other than these. The first step in the process is to define and describe the service provided by the product. In this particular research case, the service of the products made of sheep wool, particularly the ones used in the buildings, is thermal insulation.

The Danish Institute for Product Development and dk-TEKNIK has developed the Materials, Energy, Chemicals and Others (MECO) principle in co-operation with a larger Danish project $[14,15]$. The use of the principle was developed to target small and medium-sized companies. The principle divides the assessment into four areas in accordance with the underlying causes of the environmental impacts of products.

\subsubsection{Materials}

This category includes all the materials needed to produce, use and maintain the product. Materials consumption involved in the use of natural resources and consequent waste problems. Resources are considered scarce if they have a short supply horizon, which are reserves that are only sufficient for a short period given the present extraction rate. In the case of sheep wool, as a raw material, it is replenished naturally on annual basis.

\subsubsection{Energy}

This category encompasses all of the energy consumed during the product life cycle, such as the supplying of materials. Energy consumption means use of energy resources and consequent problems as global warming, nutrient enrichment and production of wastes in the form of slag, ashes or radioactive materials. The use of energy is indicated as primary energy and as use of oil resource. Primary energy is the amount of energy contained in the energy resource when extracted from Nature. The following analysis illustrates very small energy consumptions for most stages of the production of sheep wool insulation material. The energy consumption for a process was estimated from the power consumption given at the machinery name plate multiplied by the production time. This method provides a conservative estimate of the process energy. In addition, product operation and maintenance throughout the life cycle have been taken into consideration. An example of this is the energy consumed and wasted in the disposal stage. It is possible to include the total transportation as a 
separate stage to evaluate the size of energy consumption for transportation. No numerical data was provided for this aspect; therefore, analysis is purely based on distances and general fuel consumption.

\subsubsection{Chemicals}

The chemical inventory and assessment is the most difficult part of the preliminary environmental assessment performed using the MECO analytical method [14,15]. The chemicals are classified as types 1, 2 or 3 according to their environmental hazard level, with type 1 being minimum risk and type 3 being extreme risk. Chemical consumption results in effects such as toxicity to human health and the environment, stratospheric ozone depletion and photochemical ozone formation.

\subsubsection{Others}

In this category other resources and environmental problems, such as those with working environment, that have not yet been covered are looked at. Problems under the "others" category can be noise, dust, irradiation or physical impacts on humans and the environment. The completed matrix - a summary of the positive, neutral and negative environmental impacts - and any recommendation or notes are presented as part of the conclusions. The results of this analysis may lead to a future decision to carry out a more detailed environmental survey and Life Cycle Assessment with quantitative data.

\subsection{Life Cycle Check Analysis}

The scores used to assess the LCC of Bosnia and Herzegovina sheep wool as a raw material source for further production in the construction industry combined with environmental impact is illustrated (Table 6). The score range scales from 1 to 10, with 1 referring to a significantly adverse qualification and 10 to an excellent positive qualification.

Table 6. Explanation of environmental impact codes.

\begin{tabular}{cc}
\hline Score & Qualification \\
\hline 1 & Significant adverse \\
2 or 3 & Negative adverse \\
4 to 7 & Neutral \\
8 & Good positive \\
9 & Very good positive \\
10 & Excellent positive \\
\hline
\end{tabular}

\subsubsection{Material}

Sheep wool is a natural, renewable and sustainable material. Environmental impact score in this stage is 10 (excellent, positive), and there is no adverse negative effect on the environment. Sheep grow wool continuously, and if they are not sheared at least once a year, they become very stressed and uncomfortable, especially in hot and humid conditions. Sheep are therefore sheared once a year, and this does not hurt them. Some farmers shear sheep with scissors or hand blades but sometimes special machinery is used. Professional shearers are able to shear a sheep in $5 \mathrm{~min}$ and keep the fleece in one piece. 


\section{Energy}

Existing infrastructure of associations, cooperatives or farmer groups should be used for collection of information. They usually own some facilities adequate for this purpose. With traditional methods of animal husbandry, energy consumption is very sustainable. The energy required for shearing of sheep wool can be considered as relatively low, although the operation is labor intensive.

Chemicals

During the cleaning process, only hot water with a mild and eco-friendly solution should be used to remove dirt and grime. Chemical contamination of water and soil should be reduced using adequate (eco-friendly) soap (environmental impact score 7).

Other

An average commercial sheep farm with a hundred heads can produce some 50 tons of manure, which can be turned into 25 tons of compost. Part of the compost can be used for the agricultural production whereas the rest can be sold out to the market. Freshly sheared sheep need protection from the elements. It takes up to six weeks for the fleece to regrow sufficiently to provide effective insulation. Sheared sheep also require more feed to maintain their body temperatures, especially during the winter (environmental impact score 9 or 10).

\subsubsection{Production Stage}

Materials

Existing infrastructure of associations should be used to collect data. Usually they have some facilities adequate for this purpose. Depending on the facility, infrastructure and location, the environmental impact score can range from 7 to 8.

Energy

Being made from a natural fibre, production of sheep wool insulation requires less than $15 \%$ energy than glass wool insulation. Most materials collection in Bosnia and Herzegovina is performed manually (shearing), hence very little energy is needed for machines (environmental impact score 8).

As mentioned above, in the carding process, after drying, the wool passes through rollers that have thin wire teeth. The teeth untangle the fibres and arrange them into a flat sheet that is called a web. After carding, the processes used in making yarn slightly vary, depending on the length of the fibres. Further production of sheep wool into insulation paneling depends on the type of paneling.

\section{Chemicals}

The process involves removing of any stained, damaged or inferior wool from each fleece and sort the rest of the wool according to the quality of the fibres. The wool is washed to remove impurities, sand and dust (environmental impact score 6 or 7). 
Other

Lanolin wool wax, wool fat or grease, is a greasy yellow substance secreted by the sebaceous glands of sheep. Lanolin is used commercially in many products ranging from rust-preventative coatings to cosmetics and lubricants. However, no company in the former Yugoslavia produces lanolin (environmental impact score 8).

\subsubsection{Transportation Stage}

\section{Materials}

In the transportation stage, fuel takes up the largest portion of consumed materials, which depends on the distance between farm and the insulation panel manufacturing facilities. The environmental impact of materials used in transportation is by far the most significant, with an environmental impact score of 2. This stage accounts for the environmental impacts caused by the mode of transportation, such as trucking and shipping as well as packaging and distribution itself. At the moment there are no facilities in Bosnia and Herzegovina that can manufacture the necessary sheep wool panels that can be used in the building industry. Therefore, transportation of raw material to the nearest plant in Austria is inevitable.

\section{Energy}

Wool is a bulky material that occupies a lot of space. Considering the high transportation costs and the rising fuel prices, the provision of balers for compressing the wool and making it more suitable for transportation should be considered. More compact bales would decrease the volume and hence the transportation costs (environmental impact score 3).

\section{Chemicals}

The environmental impact of chemicals used in transportation is very high because they include the highest ratio for global warming potential, smog, eco-toxicological and ozone layer depletion, and depletion of minerals and fossil fuels. The LCC focused mainly on greenhouse gas measures Scope 1 (transportation vehicles) emissions (environmental impact score 1).

\subsubsection{Use Stage}

Materials

Sheep wool can absorb and break down indoor air pollutants, such as formaldehyde, nitrogen dioxide and sulphur dioxide, therefore, it can improve indoor air quality. So far, adverse effects on human or animals' health have yet to be noted (environmental impact score 10).

\section{Energy}

With the use of sheep wool insulation paneling, homes can save up to $80 \%$ on energy, cutting down on the use of fuels for heating/cooling the household and, as a result of that, substantially reducing the environmental impact. The environmental impact score here is 9-10. 


\section{Chemical}

Sheep wool insulation is safe and easy to handle, and no protective clothing or special breathing apparatus is required (environmental impact score 9-10).

Other

Causing no irritation to the eyes, skin or lungs, wool fibres present no hazards to human health. Wool fibres are breathable, they can absorb and release moisture without reducing thermal performance, unlike fibre glass based products, which makes wool a preferred insulation material. Sheep wool is inflammable and static resistant, it has very little tendency to collect static electricity because of its hygroscopic character. It also has the ability to absorb noise and thereby reduce noise levels (environmental impact score 9).

\subsubsection{Disposal Stage}

Materials

Wool is a sustainable and renewable resource that has zero ozone depletion potential, and at the end of its useful life cycle it can be remanufactured or biodegraded in Nature (environmental impact score 4-7).

Energy

Energy required to remanufacture woollen products is remarkably smaller than that in the initial stages of wool processing from raw wool (environmental impact score 9-10).

Chemical

If disposed of inappropriately (i.e., incinerated), the fumes given off from wool can be damaging to the environment (environmental impact score 2-3).

Other

Wool can cause environmental problems when thrown into rivers or burned in open fields (causing an uncomfortable smell). Therefore, it is necessary to involve competent authorities in resolving the problems related to wool collection and distribution. For example, ministries, while allocating subsidies to sheep farmers, can request a receipt from farmers that all produced wool is either sold to registered wholesaler or in some other way introduced in the official market to avoid making environmental problems (environmental impact score 2 or 3 ).

\section{Conclusions and Outlook}

Sheep wool is a natural, renewable and sustainable material, and it is important to ensure that it is used in an environmentally friendly manner. The future well-organized collection and clean production of sheep wool insulation could create a positive effect on the Bosnia and Herzegovina $(\mathrm{BiH})$ and regional 
socio-economical development through the creation of a suitable environment for farmers, SMEs, local communities. All of the aforementioned could result in enhanced standard and quality of life in rural areas. This study was focused on the alternative uses of wool as a construction material beyond its traditional uses in the textile industry. This research shows that sheep wool could be used as a very good natural resource in the building industry for insulation in $\mathrm{BiH}$ and the surrounding countries.

Local natural materials, such as sheep wool, provide sustainable answers for all requirements of contemporary architecture as appropriate materials for insulation and energy saving in buildings. Based on the results of this study, it can be concluded that thermal insulation from sheep wool provides comparable characteristics with convectional materials, and in some applications, even performs better.

Environmental strategy defines aims in terms of the concept of sustainable production and consumption. All products experience environmental degradation through their life cycle. On one hand, there is the consumption of raw materials and energy, while on the other hand, there is the emergence of adverse outputs in the form of waste and emissions. A quick LCC study revealed that, on most levels, the production and further manufacturing of sheep wool insulation panels ranks high in positive environmental impact. However, it is important that standardized and sustainable procedures are thoroughly followed through all the stages.

This research disclosed many opportunities for future scientific approaches to other possible investigation of the use of natural materials as means to produce high performance thermal insulation. Taking into consideration that $\mathrm{BiH}$ and the surrounding countries do not have a strategic plan in place for the use of this growing material, this investigation could serve as a potential starting point for positive changes that would lead to a balanced socio economic development. Ultimately, it opened the horizon for new and extensive research as well as to looking at other possible combinations of the sheep wool with local natural materials, such as clay, lime, straw, and other non-traditional usage of sheep wool in clean sustainable architecture and other sectors.

\section{Author Contributions}

Azra Korjenic contributed to Building-physics assessment and simulations made by using the HAM 3D program as well as ecological balance, Sanela Klarić contributed to the theoretical analysis and proofs, Almedina Hadžic contributed to Life Cycle assessment and Sinan Korjenic to selection of construction, writing and modification.

\section{Conflicts of Interest}

The authors declare no conflict of interest.

\section{References}

1. Berge, B. The Ecology of Building Materials; Architectural Press Linacre House: Oxford, UK, 2001.

2. Directive 2010/31/EU of the European Parliament and of the Council of 19 May 2010 on the Energy Performance of Buildings. Available online: http://eur-lex.europa.eu/legal-content/EN/ TXT/PDF/?uri=CELEX:32010L0031\&from=EN (accessed on 10 June 2015). 
3. Korjenic, A.; Petránek, V.; Zach, J.; Hroudova, J. Development and performance evaluation of natural thermal-insulation materials composed of renewable resources. Energy Build. 2011, 43, 2518-2523.

4. Zach, J.; Korjenic, A.; Petránek, V.; Hroudova, J.; Bednar, T. Performance evaluation and research of alternative thermal insulations based on sheep wool. Energy Build. 2012, 49, 246-253.

5. Torring, T.; Sandvik, K. Management of demolition waste-using life cycle assessment methodologies. In Proceedings of the International Symposium of Integrated Life-Cycle Design of Materials and Structures, Helsinki, Finland, 22-24 May 2000; pp. 522-526.

6. Doroudiani, S.; Omidian, H. Environmental, health and safety concerns of decorative mouldings made of expanded polystyrene in buildings. Build. Environ. 2010, 45, 647-654.

7. Spritzendorfer, J. Der Dämmstoff Schafwolle, Energetische Bewertung- $\mathrm{CO}_{2}$ Bilanz und Ökobilanz Beratungsagentur für zukunftsfähiges Bauen. Available online: http://www. oebag.de/fileadmin/downloads/Dateien_all_User/OEkobilanz_Schafwolle.pdf (accessed on 10 June 2015). (In German)

8. Wallbaum, H.; Ostermeyer, Y.; Salzer, C.; Zea Escamilla, E. Indicator based sustainability assessment tool for affordable housing construction technologies. Ecol. Indic. 2012, 18, 353-364.

9. Krajinovic, M. Sheep and Goat Farming (origin Ovčarstvo i kozarstvo); Agriculture Faculty, University in Novi Sad, Novi Sad, Srbia, 2006.

10. Wool Feasibility Study, researched published by UNDP BIH, June 2011. Available online: http://www.ba.undp.org/content/dam/bosnia_and_herzegovina/docs/Research\&Publications/Poverty\% 20reduction/Wool\%20Feasibility\%20Study\%20BiH.pdf (accessed on 10 June 2015).

11. Sheep Wool Potential in $\mathrm{BiH}$ and Region, Research for Cross Border Project: Association. In Proceedings of the Green Building Council, Sarajevo, Bosnia and Herzegovina, 10 November 2011.

12. Viitanen, H. Factors Affecting the Development of Mould and Brown Rot Decay in Wooden Material and Wooden Structures. Effect of Humidity, Temperature and Exposure Time. Ph.D. Thesis, Department of Forest Products, The Swedish University of Agricultural Sciences, Uppsala, Sweden, 1996; ISBN:9157651159 (pbk.).

13. Bednar, T. Baukonstruktionslehre 4; Wissen ist MANZ: Vienna, Austria, 2010.

14. Wenzel, H. Application Dependency of LCA Methodology: Key Variables and Their Mode of Influencing the Method. Int. J. Life Cycle Assess. 1998, 3, 281-288.

15. Pommer, K.; Bech, P.; Wenzel, H.; Caspersen, N.; Olsen, S.I. Handbook of Environmental Assessment of Products; Environmental Project No. 8132003 Miljøprojekt; Institute for Architecture, Miljøstyrelsen: Copenhagn, Denmark, 2000.

(C) 2015 by the authors; licensee MDPI, Basel, Switzerland. This article is an open access article distributed under the terms and conditions of the Creative Commons Attribution license (http://creativecommons.org/licenses/by/4.0/). 